\title{
Measurement of interpersonal trust in virtual software teams: A systematic literature review
}

\author{
Medición de confianza interpersonal en equipos virtuales \\ de software: Una revisión sistemática de la literatura
}

\author{
Sergio Zapata $^{1^{*}} \quad$ José L. Barros-Justo $^{2} \quad$ Gerardo Matturro $^{3} \quad$ Samuel Sepúlveda $^{4}$
}

Recibido 6 de enero de 2021, aceptado 28 de septiembre de 2021

Received: January 6, $2021 \quad$ Accepted: September 28, 2021

\begin{abstract}
The progress of Information and Communication Technologies has significantly promoted the relationships among people of different geographical regions. Under this novel context, new settings of software development teams arise, known as virtual teams. The objective is to identify, evaluate and synthesize reported research about the measurement of interpersonal trust (IpT) in virtual software teams (VST). We conducted a systematic review of the peer-reviewed literature published in the research area until July 2019. We reviewed 747 papers, of which 11 primary studies were considered relevant for the investigation. Most studies ( 8 of 11) use instruments of direct measurements (interviews and questionnaires) to measure interpersonal trust. Studies that use indirect measurements focus on different characteristics of the virtual software team (agreeableness, affective lexicon, delegation, positive tone, acceptance of knowledge, etcand others). Recomiendo: Most studies (10 of 11) report that interpersonal trust measurements improve performance aspects of virtual software teams. Among them the willingness to share information, goodwill towards others, motivation, collaboration, and effectiveness. Most studies use questionnaires or interviews, but we believe that software repository mining to obtain IpT levels will be an auspicious research trend in the future. The attribute more used to assess IpT is the developer opinion. Other attributes used are emotions, interactions between developers, biography, acceptance of knowledge, and assignment of tasks. IpT measurement is a useful tool for decision-making in VTS management, especially in agile software processes, but there is little evidence of its use.
\end{abstract}

Keywords: Interpersonal trust, virtual software teams, global software development, software process measurements, evidence-based software engineering, systematic literature reviews.

\section{RESUMEN}

El progreso de las Tecnologías de Información y Comunicación ha promovido significativamente las relaciones entre personas de diferentes regiones geográficas. En este nuevo contexto surgen novedosas configuraciones de equipos de desarrollo de software. El objetivo de Este trabajo es identificar, evaluar y sintetizar la investigación reportada acerca de la medición de confianza interpersonal en equipos virtuales de software. Llevamos a cabo una revisión sistemática de la literatura revisada por pares y publicada hasta Julio de 2019. Revisamos 747 estudios, de los cuales 11 estudios primarios fueron considerados relevantes para los propósitos de la investigación. La mayoría de los estudios (8 de 11) usan instrumentos de medición directa (entrevistas y cuestionarios) para medir confianza interpersonal. Los estudios que

\footnotetext{
1 Universidad Nacional de San Juan. San Juan, Argentina. szapata@iinfo.unsj.edu.ar

2 Universidad de Vigo. Ourense, España. jbarros@uvigo.es

3 Universidad ORT Uruguay. Montevideo, Uruguay. matturro@fi365.ort.edu.uy

4 Universidad de la Frontera. Temuco, Chile. samuel.sepulveda@ufrontera.cl

* Autor de correspondencia: szapata@iinfo.unsj.edu.ar
} 
usan mediciones indirectas se enfocan en diferentes características de los equipos virtuales de software (amabilidad, léxico afectivo, delegación, tono positivo, aceptación de conocimiento, and others). La mayoría de los estudios (10 de 11) reportan que el uso de mediciones de confianza interpersonal mejora aspectos del desempeño de los equipos virtuales de software. Entre ellos la disponibilidad para compartir información, benevolencia con los demás, motivación, colaboración y efectividad. La mayoría de los estudios usan cuestionarios o entrevistas, pero creemos que la minería en repositorios de software para identificar niveles de confianza interpersonal será una auspiciosa tendencia de investigación en el futuro. El atributo más usado para evaluar confianza es la opinión del desarrollador. Otros atributos usados son las emociones, las interacciones entre desarrolladores, la biografía, la aceptación del conocimiento y la asignación de tareas. La medición de la confianza interpersonal es una herramienta útil para la toma de decisiones en la administración de equipos virtuales de software, especialmente en procesos de software ágiles, sin embargo hay poca evidencia de este uso.

Palabras Clave: Confianza interpersonal, equipos virtuales de software, desarrollo global de software, mediciones del proceso de software, ingeniería de software basada en evidencia, revisión sistemática de la literatura.

\section{INTRODUCTION}

Advances in Information and Communication Technologies (ICT) have encouraged the relationships among people from different geographical zones, introducing new technological, cultural, and organizational challenges $[1,2]$. These challenges have led to the emergence of virtual work teams in the software development business, i.e., groups of software developers that work geographically distributed $[3,4]$.

Research has focused on understanding emotions and mood and how the human aspects of a technical discipline can affect final results and improve software quality $[5,6,7,8,9]$.

Trust is a fundamental aspect of cooperative work in software development [10]. This fundamental aspect is the current case in collocated software teams, but it is even more important in a virtual team environment [11]. Trust is believed to be the fundamental factor in determining the success or failure of virtual teams $[12,13,14,15]$.

Mayer et al. [16] define trust as "The willingness of a party to be vulnerable to the actions of another party based on the expectation that the other will perform a particular action important to the trustor, irrespective of the ability to monitor or control that other party". Trust allows people to participate in risky activities that they cannot control or monitor and even in which they may be disappointed by the actions of others [17].
Research shows that teams with high degrees of trust are more proactive and optimistic, focus on task results, interact more frequently, and provide productive feedback. [18].

Teams with high levels of trust are associated with high productivity and member satisfaction [19]. The teams can be successful without trust, but they tend to bear additional costs such as monitoring teammates and backing up their work [20].

Trust is a relevant aspect of global software development (GSD); it must be measured and controlled. Software measurement techniques promise to improve the control of the development process, reduce development time and costs, and produce higher quality software [21]. Software measures have been touted as essential resources for improving quality and controlling costs during software development [22].

If a low level of IpT (interpersonal trust) is measured Recomiendo: Most studies (10 of 11) report that interpersonal trust measurements improve performance aspects of virtual software teams.

In that case, leaders in the process could promote faceto-face meetings [23, 24], new leadership styles [25, 26], new software tools [11, 27, 28], ad-hoc training $[28,29]$, and other initiatives to enhance trust level.

The purpose of this work is to identify, evaluate and synthesize reported research about the measurement 
of IpT in VST. To achieve this goal, we applied a research technique known as Systematic Literature Review (SLR). The SLR is an indirect (secondary) research method that does not face the ethical and bias issues typically associated with direct methods. An SLR aims to be as objective, analytical, and repeatable as possible [30].

This work is a contribution to the software engineering community, especially for leaders or managers of VST. The results will allow knowing the different aspects of the IpT measurements in these workgroups and thus applying the best practices.

The rest of this work is structured as follows: Related Work section describes the results from other related studies; Research Method section details the research method applied in this work; Results and Synthesis section presents the results, synthesis, and discussion of the extracted data, whereas Validity Threats section exposes threats to results validity. Finally, the Conclusions and Future Work section present the conclusions and some proposals for future research.

\section{RELATED WORK}

After conducting extensive searches in several electronic data sources (online databases, publisher sites, and general search engines), we have found five secondary studies about interpersonal trust in VST.

The study of Niazi et al. [31] presents a systematic literature review aimed to identify important factors for establishing trust in offshore software outsourcing relationships. In that paper, trust is analyzed for the client vendor's relationship and is defined as clients and vendors having positive expectations of each other's actions. The authors discovered that faceto-face meeting, better communication, contract management between client and vendor, defining process tools, procedures and policies, and reliable management play an important role in establishing trust between clients and vendors, in the context of offshore software outsourcing relationships. This paper only considers trust between clients and vendors.

The goal of da Silva et al. paper [23] is to build an evidence-based model of distributed software development project management from the research findings of challenges of DSD. The authors based the construction of their model on the evidence collected and synthesized by a comprehensive SMS containing 70 research papers published between 1997 and 2009. Specifically, this work identifies practices and traditional communication tools that would favor the IpT in DSD. The main practices identified to promote IpT are providing training in collaboration and coordination tools, using and maintaining common software processes among worksites dividing the work into well-defined modules and carrying out progressive integration. The most important communication tools identified are phone (including teleconference and audio conference), emails, and video conferences. In all cases, these tools are supported by traditional (noninnovative) technology. This SMS does not involve issues of IpT measuring, which is of interest to our research. Recomiendo: Most studies (10 of 11) report that interpersonal trust measurements improve performance aspects of virtual software teams.

Zapata et al. [32] conducted a systematic mapping study up to August 2016 to assess the impact of virtual team's IpT on the software development process. This study identified some work strategies but few advanced tools to mitigate the problems derived from the lack of IpT. The authors conclude that IpT in virtual development teams has not been investigated in-depth, despite the researchers pointing. Most studies (10 of 11) report that interpersonal trust measurements improve performance aspects of virtual software teams.

out the strong impact it has on software development, both in productivity and quality. Communication tools would significantly improve the building and maintenance of trust in virtual teams. However, this SMS does not include aspects of IpT measuring.

Tyagi et al. [33] present a lightweight systematic review for investigating the role of trust in distributed agile software development projects. The work provides a comprehensive overview of the studies related to the role of trust in a distributed agile environment and identified different challenges faced by agile teams working in a distributed environment that includes lack of face-to-face communication, different cultural backgrounds, linguistic barriers, and different time zones. Key factors like poor socialization among team members, missing 
face-to-face interactions, and unpredictability in communication are identified as causes for lack of trust in GSD teams. This work also does not cover the issue of IpT measurement.

In our study, we expose a systematic literature review up to July 2019 aimed to identify, evaluate and synthesize reported knowledge about the measurement of IpT in VST.

The related works analyzed to address the factors to establish trust, relationships between trust and knowledge, practices and tools to build trust, the impacts, and role of trust in virtual teams. However, the measurement of trust in a virtual team, as far as we know, has not yet been addressed in secondary studies.

\section{Research Method}

This research is grounded on the Evidence-Based Software Engineering (EBSE) paradigm. As explained in Kitchenham et al. [30], EBSE is concerned with determining what works, when, and where, in terms of software engineering practice, tools and standards. The key activities to conduct this study was defined in a research protocol ${ }^{5}$, which application is detailed in the following sections.

The SLR aims to identify, evaluate, and synthesize reported knowledge about the measurement of IpT in VST. The need for a systematic review arises from the requirement of researchers to summarize all current information about some phenomenon in a thorough and unbiased manner [34]. Our interest is focused on IpT measurement techniques, measured attributes, software development methodologies where these techniques have been applied, and the usefulness of the measurement. To this end, we established the research and publication questions shown in Table 1.

\section{Search strategies}

According to Wohlin [37], the completeness of the search in an SLR is very important. In the case of a systematic review comparing software engineering technologies (or techniques), completeness is a critical issue [30]. Therefore, we decided to apply complementary searches to achieve the most

\footnotetext{
5 https://github.com/
}

significant completeness, as possible, of the results of the search process.

A combined search strategy was used; it included automated search in databases, manual search in relevant conferences, and snowballing search. Figure 1 shows the application of these techniques during the SLR execution process. The result of this search process was the set of candidate studies.

We used five online scientific databases in this automated search: ScienceDirect, SpringerLink, Scopus, IEEEXplorer and ACM Digital Library as electronic data sources. These are the most cited electronic data source in literature review guidelines $[30,38,39,40]$.

\section{We used the following search string:}

("Interpersonal trust" OR trust OR confidence) AND ( measurement OR measure OR metric OR indicator OR evaluation OR assessment OR level OR compute OR degree OR estimation OR calculate OR quantification) AND ("global software development" OR "global software engineering" OR "distributed software development" OR "distributed software engineering" OR "global system development" OR "global system engineering" OR "distributed system development" OR "distributed system engineering" OR "global software project" OR "distributed software project" OR GSD OR GSE OR DSD OR DSE OR "cross-continent software engineering" OR "cross-continent software development" OR "global software team" OR "distributed software team" OR "virtual software team" OR "remote software team" OR "offshore software team" OR "collaborative software team" OR "cross-continent software team").

A complementary, manual search was performed by manually reviewing the proceedings of the International Conference of Global Software Engineering $^{6}$ (ICGSE), International Conference of Software Engineering ${ }^{7}$ (ICSE) and Empirical Software and Metrics Conference ${ }^{8}$ (ESEM). These are the leading conferences on Global Software Engineering, general topics of Software Engineering and Software Metrics, respectively.

\footnotetext{
6 icgse.org

https://www.icse-conferences.org/

8 http://esem-conferences.org/
} 
Table 1. Description of Research and Publication Questions.

\begin{tabular}{|c|l|}
\hline Question & \multicolumn{1}{c|}{ Description } \\
\hline RQ1 & $\begin{array}{l}\text { Which measurement techniques are used to measure IpT in VST? } \\
\text { Data to be extracted will include: The type of measurement used (objective, subjective, direct, } \\
\text { indirect) [35], instruments of measurement used (questionnaire, interview, formula), and the time } \\
\text { of the software development process when the measurement was performed (before, during, after). }\end{array}$ \\
\hline RQ2 & $\begin{array}{l}\text { Which attributes are used to measure IpT in VST? } \\
\text { We want to know which attributes are measured to obtain grades or levels of IpT in VST. Some } \\
\text { attributes could be personal opinions, among team members' interactions, team members' emotions, } \\
\text { degree of knowledge exchange, and others. }\end{array}$ \\
\hline RQ3 & $\begin{array}{l}\text { What aspects are affected by IpT measurement-based decisions? } \\
\text { Decisions based on IpT measurements can be applied to process aspects (promote face-to-face } \\
\text { activities), to team aspects (coach to team members with low interpersonal trust), or to tools used in } \\
\text { VST (promote communication tools that support social interactions). }\end{array}$ \\
\hline RQ4 & $\begin{array}{l}\text { Which software development processes are reported? } \\
\text { We aim to identify and classify the software development process where IpT measurement in VST } \\
\text { is applied. These processes could be agile (Scrum, Kanban, XP, and others.) or plan-drives (RUP, } \\
\text { Prototyping, Waterfall, and others.). }\end{array}$ \\
\hline PQ1 & $\begin{array}{l}\text { Which research types are reported? } \\
\text { We used the classification proposed by Wieringa et al. [36] including: Validation research, evaluation } \\
\text { research, solution proposal, philosophical papers, opinions papers, and experience papers. }\end{array}$ \\
\hline PQ2 & $\begin{array}{l}\text { Which are the main publication venues? } \\
\text { We considered scientific Journals, Conferences, and Workshops. The extracted data should include } \\
\text { the name of the venue and publishing year. }\end{array}$ \\
\hline
\end{tabular}

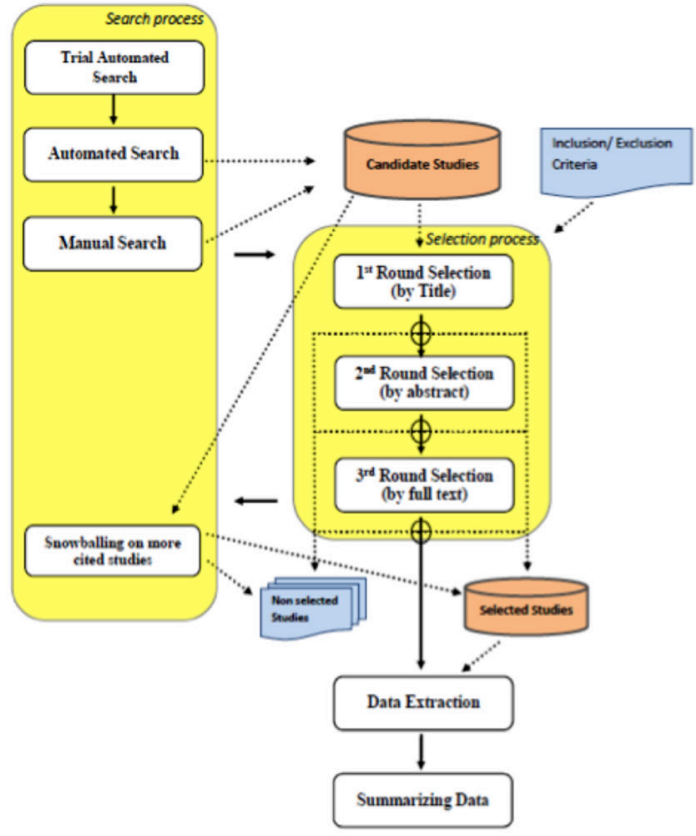

Figure 1. SLR execution process.

Snowballing is a search approach that uses the reference list of a paper or its citations to identify additional studies. The snowballing process is an iterative process described in Wohlin [35] and involves two complementary sub-process, backward snowballing and forward snowballing. In our case, snowballing was used as a complementary search method, and it was carried after the execution of automated and manual search methods.

\section{Selection strategy}

The selection strategy was divided into three phases or rounds, as shown in Figure 1. The set of candidate studies, the outcome of the search strategy, was the input of the selection process, which was grounded on the guidelines proposed in Petersen [41].

We conducted three rounds of the selection process, including selection by title (1st round), selection by abstract (2nd round), and selection by full text (3rd round). If a study was selected in one round, then this paper was not analyzed in the following rounds. A paper was selected if it was pertinent for the SLR, i.e., if it meets inclusion criteria and did not meet exclusion criteria (see Table 2).

The selection process aimed to identify a set of relevant papers by applying inclusion/exclusion criteria to candidate studies. The principal researcher (first author) defined the inclusion/exclusion criteria, 
Table 2. Inclusion/Exclusion Criteria.

\begin{tabular}{|c|l|}
\hline$\#$ & \multicolumn{1}{|c|}{ Inclusion Criteria } \\
\hline IC1 & Papers written in English. \\
\hline IC2 & $\begin{array}{l}\text { Papers published in Journals indexed by the JCR or in International Conferences with a peer-reviewed } \\
\text { acceptance system. }\end{array}$ \\
\hline IC3 & Papers focused in measurement of interpersonal trust in virtual software teams. \\
\hline$\#$ & \multicolumn{1}{c|}{ Exclusion Criteria } \\
\hline EC1 & Grey literature (slides presentations, posters, tutorials, forewords, keynote speeches, letters, and others). \\
\hline EC2 & Short papers (less than 4 pages). \\
\hline EC3 & Duplicate reports of the same study (we consider only the most recent one). \\
\hline
\end{tabular}

reviewed and agreed by the second author. In cases of disagreement, the opinion of the third author was imposed.

By applying the search and selection process, we selected 11 primary papers (see subsection Selected Studies in References). Figure 2 shows these processes and intermediate results.

\section{Extraction of data}

This section defines the process performed to extraction and validation of data from a set of selected studies. The extracted data included publication details and the information needed to answer the research questions [30].

The extraction of data was carried out by reviewing the set of selected studies. The full text of each study was read to extract data to answer every RQs and PQs listed in Table 1. Data items were extracted from each paper are shown in Table 3. an identifier number was assigned to each selected study (see Selected Studies subsection in References) to keep traceability between processes.

\section{RESULTS AND SYNTHESIS}

This section aims to summarize, integrate, combine and compare [30] the findings obtained from the selected primary papers to synthesize new knowledge. We followed the recommendations of Kitchenham [30], Popay [43], and Wohlin [35] to conduct the synthesis process. To, 3 subsections will be presented: Summarizing data, Answering RQs, and Discussion.

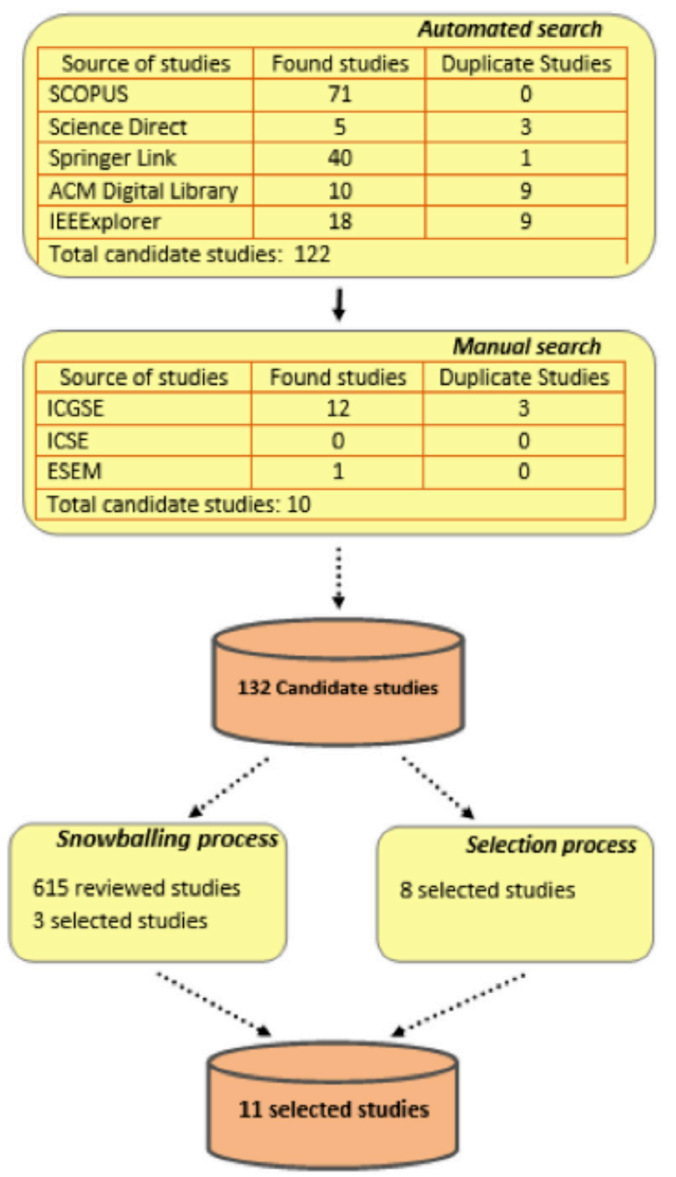

Figure 2. Results of searching and selection process.

\section{Summarizing Data}

This section, presents the extracted data from the set of selected studies for each data element defined in Table 3. 
Table 3. Data Items to be extracted from studies.

\begin{tabular}{|c|l|l|l|}
\hline \# & \multicolumn{1}{|c|}{ Data Item } & \multicolumn{1}{|c|}{ Description } & Relevant to \\
\hline D1 & Title & The title of the paper. & Overview \\
\hline D2 & Authors List & The full name of all authors of the paper. & Overview \\
\hline D3 & Abstract & The abstract of the paper. & Overview \\
\hline D4 & Year & Year when the paper was published. & Overview \\
\hline D5 & Type of research & $\begin{array}{l}\text { Validation research, Evaluation research, Solution Proposal, } \\
\text { Philosophical papers, Opinions papers, Experience papers. [36] }\end{array}$ & PQ1 \\
\hline D6 & Venue & The name of the venue where the study was published. & PQ2 \\
\hline D7 & Type of Venue & Journal or Conference. & PQ2 \\
\hline D8 & Type of measurement & Direct/Indirect, Objective/Subjective, [35] No report. & RQ1 \\
\hline D9 & Measurement Instrument & Interview, Questionnaire, Counter, Other, No report. & RQ1 \\
\hline D10 & Measurement Time & Before, During, After respect to software process. & RQ1 \\
\hline D11 & Measured attributes & $\begin{array}{l}\text { Interactions, Emotions, knowledge Exchange, Member biography, } \\
\text { Member Opinion, Other, No report. }\end{array}$ & RQ2 \\
\hline D12 & $\begin{array}{l}\text { Affected aspects by the IpT } \\
\text { measurements based decisions. }\end{array}$ & Software process, team, tolos, Other, No report. & RQ3 \\
\hline D13 & $\begin{array}{l}\text { Type of software development } \\
\text { process }\end{array}$ & $\begin{array}{l}\text { Plan-drive, Adaptive, Agile methodologies, [42] Other, Several, No } \\
\text { report. }\end{array}$ & RQ4 \\
\hline D14 & $\begin{array}{l}\text { Software development process } \\
\text { name }\end{array}$ & Scrum, XP, Kanban, Waterfall, RUP,/Other, No report. & RQ4 \\
\hline
\end{tabular}

Year of publication. The studies $[68,71]$ were the first works about IpT measurements in GSD, published in 2010. In Table 4, we show the publication year of the selected studies.

Type of research. Most of the selected studies are evaluation research, according to Wieringa [36]. In Table 5, we show the type of research of the selected studies.

Venue. In Table 6, we show several venues where the selected studies were published.

Type of venues. There is a uniform distribution of studies published in journals and conferences; Table 7 shows this information.

Table 4. Year of publication.

\begin{tabular}{|c|c|c|}
\hline Year & \# studies & Studies \\
\hline 2010 & 2 & {$[68,71]$} \\
\hline 2011 & 1 & {$[65]$} \\
\hline 2012 & 1 & {$[73]$} \\
\hline 2013 & 1 & {$[70]$} \\
\hline 2016 & 2 & {$[64,67]$} \\
\hline 2017 & 3 & {$[63,69,72]$} \\
\hline 2018 & 1 & {$[66]$} \\
\hline
\end{tabular}

Table 5. Type of research.

\begin{tabular}{|l|c|c|}
\hline \multicolumn{1}{|c|}{ Type of research } & \# Studies & Studies \\
\hline Validation research & 3 & {$[64,66,67]$} \\
\hline Evaluation research & 8 & $\begin{array}{c}{[63,65,68,69,70,71,} \\
72,73]\end{array}$ \\
\hline Solution Proposal & 0 & \\
\hline Philosophical papers & 0 & \\
\hline Opinions papers & 0 & \\
\hline Experience papers & 0 & \\
\hline
\end{tabular}

Type of measurement. We found 8 studies that reported direct and subjective measurements of IpT and 4 studies that reported indirect and objective measurements ( see Table 8). The study [67] used both types of measurement. No other type of measurement was identified in the set of selected studies.

Indirect and objective measurements are performed automatically, without human intervention, based on the recorded data during software development in version control systems (VCS), especially GitHub ${ }^{9}$.

9 https://github.com/ 
Table 6. Venues of the selected studies.

\begin{tabular}{|l|c|c|}
\hline \multicolumn{1}{|c|}{ Venue } & \# studies & Studies \\
\hline International Conference on Global Software Engineering (ICGSE) & 2 & {$[63,65]$} \\
\hline International Workshop on Emotion Awareness in Software Engineering & 1 & {$[64]$} \\
\hline Information and Software Technology (Elsevier Journal) & 1 & {$[66]$} \\
\hline Empirical Software Engineering (Springer Journal) & 1 & {$[67]$} \\
\hline Int conference on Software Engineering Approaches for Offshore and Outsourced Development. & 1 & {$[68]$} \\
\hline Management Accounting Research (Elsevier Journal) & 1 & {$[69]$} \\
\hline European Conference on Information Systems & 1 & {$[70]$} \\
\hline ACM-IEEE International Symposium on Empirical Software Engineering and Measurement & 1 & {$[71]$} \\
\hline Information \& Management (Elsevier Journal) & 1 & {$[72]$} \\
\hline R\&D Management (RADMA Journal) & 1 & {$[73]$} \\
\hline
\end{tabular}

Measurement Instrument. A homogeneous use of the three types of measuring instruments can be observed identified in the set of selected studies, see Table 9. No other type of measuring instrument other than the interview, questionnaire and counter (formula) has been reported.

The papers that informed the use of interviews did not follow a standard method; each study applied an ad-hoc interview.

Only the study [67] applied its ad-hoc questionnaire regarding studies that used questionnaires as a measuring instrument. While $[70,72,73]$ used questionnaires already reported in the specific scientific literature, in Deutsch [44], Jarvenpaa and Leidner [45], and Hertel et al. [46]

Studies that used counting (formula) focus on different characteristics or attributes of the VST members and the software development process

Table 7. Type of venues.

\begin{tabular}{|l|c|c|}
\hline $\begin{array}{c}\text { Type of } \\
\text { Venue }\end{array}$ & \# studies & Studies \\
\hline Journal & 5 & {$[66,67,69,72,73]$} \\
\hline Conference & 6 & {$[63,64,65,68,70,71]$} \\
\hline
\end{tabular}

Table 8. Type of measurement.

\begin{tabular}{|l|c|c|}
\hline Type of measurement & \# studies & Studies \\
\hline Direct and subjective & 8 & $\begin{array}{l}{[65,67,68,69,} \\
70,71,72,73]\end{array}$ \\
\hline Indirect and Objective & 4 & {$[63,64,66,67]$} \\
\hline
\end{tabular}

Table 9. Measurement instrument.

\begin{tabular}{|l|c|c|}
\hline Measurement Instrument & \# Studies & Studies \\
\hline Interview & 4 & {$[65,68,69,71]$} \\
\hline Questionnaire & 4 & {$[67,70,72,73]$} \\
\hline Counter & 4 & {$[63,64,66,67]$} \\
\hline Other & 0 & \\
\hline No reported & 0 & \\
\hline
\end{tabular}

that are evidence of IpT according to scientific literature [47, 48, 49, 50, 51, 52].

Three studies that applied counting used tone analysis tools, such as IBM Watson [63] and SentiStrength $[64,66]$, to evaluate IpT. Furthermore, these three studies used the GitHub VCS as a source of data collection, especially the interactions recorded among the VST members.

The study [66] evaluated IpT by measuring various aspects or characteristics, see Table 10. It established a formula with weights to reach a final single indicator.

Measurement Time. Most studies (9) applied the measurements during the software process or finished it, see Table 10. There are 3 studies that do not report when measurements were made. 65 made measurements on ongoing software projects and also on recently finished projects.

Measured Attributes. Most studies (7) directly measured the developer's perception of IpT through questionnaires or interviews; Table 11 shows this information. Two other studies evaluated emotions expressed textually in exchanged messages, as 
Table 10. Measurement time.

\begin{tabular}{|l|c|c|}
\hline Measurement Time & \# studies & Studies \\
\hline After the process & 5 & {$[63,65,67,71,73]$} \\
\hline During the process & 4 & {$[65,66,68,69]$} \\
\hline Before the process & 0 & \\
\hline No reported & 3 & {$[64,70,72]$} \\
\hline
\end{tabular}

Table 11. Measured attributes.

\begin{tabular}{|l|c|c|}
\hline \multicolumn{1}{|c|}{ Measured Attributes } & \# studies & Studies \\
\hline Process member Opinions & 7 & $\begin{array}{c}{[65,68,69,} \\
70,71,72,73]\end{array}$ \\
\hline Process member Emotions & 2 & {$[64,66]$} \\
\hline $\begin{array}{l}\text { Process member Interactions } \\
\text { (other aspects evaluated } \\
\text { from the interactions) }\end{array}$ & 3 & {$[63,66,67]$} \\
\hline Process member biography & 1 & {$[66]$} \\
\hline Knowledge Exchange & 1 & {$[66]$} \\
\hline Other & 1 & {$[66]$} \\
\hline No reported & 0 & \\
\hline
\end{tabular}

evidence of IpT. Thus, [64] measured affective lexicon, and [66] measured positive tone.

3 studies focused on the exchanged interactions (messages) by team members and measured different aspects that, according to them, are evidence of IpT. The study [63] measured agreeableness, [66] measured vocabulary similarity, delegation, trustworthiness, and collaboration. Finally, [67] measured insignificant conversations (cheap talks) as evidence of IpT.

Regarding the biography and knowledge sharing, both attributes are used in [66].

It should be remarked that [66] is the only study that evaluated IpT by composing attributes of different types, such as emotions, interactions polarity, member biography, knowledge acceptance, and task assignment. In the latter case, it used the register of pull request assignments of GitHub. A pull-request is a request for a new source code review to incorporate it in the final software version in production. In this review, the team members work collaboratively, registering their actions and interactions in the VCS.

The task assignment is not included in the data classification scale, so [66] was also classified as "Other".
Affected aspects. Most of the studies (8) reported using the IpT measurements for decision-making on performance aspects of virtual software teams (see Table 12). Among them the availability to share information in $(64,65,72]$, goodwill towards others in [64], individual motivation in [70], collaboration in [64, 72], and effectiveness in [73]. The configuration of teams based on the IpT measurement is another aspect that the studies [66, 68,69 ] proposed, although there is no evidence of the application of this practice.

The relationship between IpT measurements and process activities is highlighted in the studies [63, 67]. The IpT measurements are used to predict the quality of the results of the process activities; for example, in [63] the IpT level predicts the success or acceptance of pull requests (i.e., if the new source code is merged in the final version of the software in production).

Only the study [67] reported that the IpT measurement could be used to improve process tools. No studies were found that reported other aspects that IpT assessments could improve.

Type of software development process. No selected study mentioned the type of software development process used during the IpT evaluation.

Name of Software Process. No selected study mentioned the software process name used during the IpT evaluation.

\section{Answering RQs}

In this section, based on the previously summarized data, the research questions raised in the SLR are answered.

Regarding RQ1: Which measurement techniques are used to measure IpT in GSD?. The analyzed data

Table 12. Affected aspects.

\begin{tabular}{|l|l|c|}
\hline \multicolumn{1}{|c|}{ Affected aspects } & \# Studies & Studies \\
\hline Development Team & 8 & $\begin{array}{c}{[64,65,66,68,} \\
69,70,72,73]\end{array}$ \\
\hline Process activities & 2 & {$[63,67]$} \\
\hline Process Tools & 1 & {$[67]$} \\
\hline Other & 0 & \\
\hline No reported & 1 & {$[71]$} \\
\hline
\end{tabular}


items to answer RQ1 were the type of measurement, measurement instrument, and measurement time.

Most of the selected studies reported direct and subjective measurements by applying questionnaires or ad-hoc interviews. The extensive use in the social sciences of qualitative methods to measure human aspects [53], especially in working groups, could be the reason for the majority choice of these techniques.

The four studies that used indirect and objective measurements (formula) are of recent publication, $[64,67]$ in 2016, [63] in 2017, and [66] in 2018. This recent increasing use of VCS, such as GitHub, and the increasing application of text and data mining techniques in software engineering [54] may explain these phenomena.

Most studies carried out the measurements during or after the software development process, and only once, even though the IpT can change during the process [13]. Thus, applying only one measurement during the entire software development cycle would not be an appropriate strategy to monitor IpT in VST.

No studies evaluated IpT before beginning the software process. This is evidence of the lack of use of this evaluation when creating software development teams. Beyond that, some selected studies, as $[68,68,69]$, suggest this use.

In indirect and objective measurements, the direct participation of the work team members is not required. All four studies used this type of measurement used automated measurements using the data (messages, assigned tasks, logs, access to documents, and others.) recorded in VCS during the software development process. This automated way encourages the repetition of the measurement, in real-time, during the entire software development cycle.

Regarding RQ2: Which attributes are used to measure IpT in GSD?. The analyzed data item to answer RQ2 was measured attribute.

We find that the more used attribute to assess IpT was the developer opinion. This characteristic follows the seminal studies on IpT evaluation in collocated work teams $[16,45]$. Because team members can feel uncomfortable evaluating their teammates, the obtained opinion can be biased. Some researchers have reported the fear of job loss for some developers in virtual software development scenarios [11,28, 55], which contributes to creating an inappropriate environment for gathering objective opinions about interpersonal relationships.

Other measured attributes were emotions (measuring affective lexicon and positive tone), interactions between developers (measuring agreeableness, vocabulary similarity, trustworthiness, collaboration, and cheap talks), biography, acceptance of knowledge, and assignment of tasks (delegation).

Regarding RQ3: What aspects are affected by IpT measurement-based decisions?. The affected aspect data item was analyzed to answer RQ3. Most of the selected studies propose using IpT evaluation to improve aspects related to the software development team, for example, availability to share information, goodwill towards others, individual motivation, collaboration, and proper configuration of new development teams.

Very few studies report that decisions based on the measurement of IpT can be applied to improve aspects related to process activities or development tools. It would be expected that the tools used in the software development process, especially the communication tools, could adapt their functionality based on the IpT levels of the team members.

Regarding RQ4: Which software development processes are reported?. The analyzed data items to answer RQ4 were the type of software development process and the name of the software process.

The selected studies do not report data on the type or name of the software development process applied. This unreported information indicates that the kind of software development process is not decisive for the intention of applying IpT measurements.

\section{DISCUSSION}

Some studies applied direct and subjective measurements, using questionnaires or interviews, once the software development was finished. Other studies applied the same type of measurement but during the software development process. A similar situation is observed in studies that used indirect 
and objective measurement. There is no relationship between the type of IpT measurement and the moment in which they are applied. The choice of the type of measurement does not depend on the timing of the measurement; but on other criteria. For example, availability of the developers (necessary for an objective and direct measurement), cost of implementation, the number of repetitions of the measurement, and others.

The levels of IpT fluctuate during the software development cycle $[13,55,56]$. Therefore, it is appropriate to asset the IpT at different times of the software process to analyze its evolution. In this case, automated measurements based on VCS data are easier to apply and less invasive to team members. Measuring instruments, such as interviews and questionnaires, which require the active participation of team members to evaluate IpT, can be uncomfortable for them. They may feel conditioned by the working or social bond when evaluating their partners [52]. In addition, the process of data collection and calculation is expensive and heavy (not agile) when applying these instruments of direct and subjective measurement. This application discourages the repeated application of the measurement during the software development process.

Trust in virtual teams needs to be developed rapidly because teams may only interact for a short time [13, 45]. Hence, measurements in the initial stages of the software development process could be very useful. However, no selected study applies or encourages early IpT evaluations. In the case of direct and subjective measurements based on interpersonal opinions, this may be due to the need for a deep and prolonged relationship among VST members so that developers can give reliable opinions about their teammates. While in the case of indirect and objective measurement, based on VCS data, early measurements on a small data size would be of low reliability. The identifying of early reliable methods for IpT measurement is a research area to address. The use of the concept of swift trust [56] could be helpful to approach this research.

A strong relation is observed between measured attributes and measurement types. Studies $[65,68$, $69,70,71,72,73]$ that focus on the evaluation of IpT through the opinion of team members apply direct and subjective techniques, such as interviews and questionnaires. While studies that focus on IpT evidence, such as measuring agreeableness, vocabulary similarity, trustworthiness, collaboration, cheap talks, acceptance of knowledge, and assignment of tasks, apply indirect and objective techniques (formula).

The questionnaires based on Jarvenpaa and Leider [45] and Mayer et al. [16] papers measure instruments that address the three main factors of IpT, benevolence, ability, and integrity. On the contrary, indirect and objective measurements, applied in the selected studies, evaluate only some of them. This assessment may be due to the lack of research on the CVS data to obtain metrics that evidence those three components of IpT.

By analyzing extracted data of selected studies rises that:

- If the aim is to monitor IpT during the entire software development process to make decisions regarding VST performance, then the best alternative would be to apply indirect and objective measurements, as the proposals in $[63,64,66]$. Since these measurements are less invasive, easier to repeat, faster to apply, and less expensive. There exist several researches that report attributes that evidence IpT. According to selected studies, the more used attributes are agreeableness, affective lexicon, vocabulary similarity, assignment, trustworthiness, positive tone, knowledge acceptance, and collaboration.

- If the aim is to understand the role of IpT in VST, then direct and subjective measurements are more suitable, such as those applied in $(65,68,69,70,71,72,73)$. The use of questionnaires or interviews can yield more detailed information regarding different aspects of IpT. The questionnaires most commonly used in the selected studies are those proposed in Jarvenpaa and Leider (45) and Mayer et al. [16] are the most applied in the selected studies.

Humphrey [57] asserts that when a trusting relationship is assumed, the development process has a new degree of freedom; requirements can be handled more sensibly, and a great deal of expensive documentation can be avoided. Interpersonal relationships among members of the development teams are especially taken into account in the agile 
software development methods $[58,59]$. However, in the results of this SLR, there is no evidence that agile development practitioners have a particular interest in IpT measurements.

In the big data era, large volumes of data are continuously generated. Thus, the increasing use of VCS repositories, such as GitHub, and the growth of the Mining Software Repositories research [54] could encourage the application of indirect and objective measurements to grow in the future. We believe it is necessary to increase research on the reliability of measurements based on IpT evidence.

Regarding tools to support the collaborative work in VST, Al-Ani et al. [60] affirm that they need to be more comprehensive to be useful to all team members irrespective of their role. Integrating IpT measurements in VST could be helpful to global software team managers.

\section{VALIDITY THREATS}

The following types of validity should be taken into account [41]:

1. Descriptive validity: Threats associated with the description of data and observations (potential bias of the researchers).

2. Theoretical validity: Two different activities can be affected, the identification/selection of papers (missed studies) and data extraction and classification (researcher bias).

3. Interpretive validity: Conclusions drawn are reasonable given the data (researcher bias).

4. Repeatability: The possibility that other researchers obtain the same results by following the same processes (lack of details).

Using several sources for the automatic search of the primary papers, the second strategy of manual search and finally applying the snowballing techniques to complement the results reduce the risk of missing some important work.

Four authors formed two teams of two researchers to reduce researcher bias during the identification and selection process, each that worked independently by conducting a redundant selection.

We used the Kappa score [61] to validate the study's selection process. Discrepancies over the qualification of each study between researchers were resolved following the guidelines from Wohlin [37].

To minimize these potential threats to the validity of this work, we developed a standard form for data extraction and analysis (DEF). All authors independently filled out this DEF, and the first author integrated the results. The agreement between independent assessors is used to assess the validity of the data extraction. When discrepancies arose over the interpretation of the data, they were resolved through virtual meetings. The Kappa score for these activities reached a value of $75 \%$ in agreement. Hence, we consider this threat to be well controlled.

To facilitate the repetition of the study, we elaborated a detailed protocol of the current SLR to all interested researchers.

\section{Conclusions and future work}

The objective of this study was to identify, evaluate and synthesize reported knowledge about the measurement of IpT in VST. In order to, we conducted a systematic review of the peer-reviewed literature published until July 2019. During the SLR process, we reviewed 747 articles, of which 11 were selected to analyze in-depth.

Software development is a human activity and, as such is prone to continuous performance improvements. Software measurement is the approach to controling and managing the software process and to tracking and improving its performance. Electronic performance monitoring systems that report feedback information on team members are very important for decision-making [46, 62], even in virtual team management. The present work identifies several IpT measurement techniques that can be applied to reach more effectiveness in VST.

Measuring IpT of software developers could be more interesting than measuring their capabilities since it is included in the former. According to the literature, trust involves ability, benevolence, and integrity. In other words, knowing the IpT levels of the developers is much rich than knowing their capabilities.

Nowadays, the agile software development methods are much extended. These methods highlight human aspects over processes. Measure IpT in software 
development teams could contribute to monitoring the human behavior in these teams. Thus the use of CVS-based automated measurement, proposed by this paper, could be helpful. This automated measurement facilitates the replication of the measurement process during all software development cycles, and it is less invasive to developers.

The attribute more used to assess IpT is the developer opinion. Other used attributes are emotions (measuring affective lexicon and positive tone), interactions among developers (measuring agreeableness, vocabulary similarity, trustworthiness, collaboration, and cheap talks), biography, acceptance of knowledge, and assignment of tasks.

Most studies use direct and subjective measurements, such as questionnaires and interviews, However, we believe that software repositories mining to obtain IpT levels will be an auspicious research trend in the future.

We did not find studies evaluating IpT before beginning the software process. This is evidence of the lack of use of this evaluation at the time of the creation of software development teams. The identifying of early reliable methods for IpT measurement is a research area to address.

In the selected studies, we have not found rigorous mechanisms to validate the reliability of the proposed measurements, especially those that deal with evidence of IpT. This evidence is a reason by which we consider that the IpT measurement process is still immature, another area that future research should address.

Our SLR only found 11 studies on the measurement of IpT in VST; we believe that incremental research on this subject should be carried out to reach a deep and encompassing knowledge that allows generalized results.

\section{REFERENCES}

[1] M. Cataldo. "Dependencies in geographically distributed software development: Overcoming the limits of modularity". Dissertation Abstracts International. Vol. 68 $\mathrm{N}^{\circ} 12.2007$.

[2] B.H. Malik, S. Faroom, M.N. Ali, N. Shehzad, S. Yousaf, H. Saleem and K. Khan.
"Geographical distance and communication challenges in global software development: A review". International Journal of Advance Computer Science and Applications. Vol. 9 No 5, pp. 406-414. 2018.

[3] M. Alsharo, D. Gregg and R. Ramirez. "Virtual team effectiveness: The role of knowledge sharing and trust". Information \& Management. Vol. 54 N $^{\circ}$ 4, pp. 479-490. 2017.

[4] G.R. Berry. "Enhancing effectiveness on virtual teams: Understanding why traditional team skills are insufficient". Journal of Business Communication. Vol. $48 \mathrm{~N}^{\circ} 2$, pp. 186-206. 2011.

[5] L.F. Capretz and F. Ahmed. "Making sense of software development and personality types". IT Professional. Vol. $12 \mathrm{~N}^{\circ}$ 1, pp. 6-13.2010.

[6] A. Cockburn and J. Highsmith. "Agile software development, the people factor". Computer. Vol. No 11, pp. 131-133. 2001.

[7] D. Graziotin, X. Wang, P. Abrahamsson. "Happy software developers solve problems better: Psychological measurements in empirical software engineering". Vol. 2, e289. 2014. DOI: 10.7717/peerj.289.

[8] N. Novielli, F. Calefato and F. Lanubile. "Towards discovering the role of emotions in stack overflow". 6th international workshop on social software engineering ACM, pp. 32-36. 2014.

[9] M. Ortu, G. Destefanis, S. Counsell, S. Swift, R. Tonell and M. Marchesi. "How diverse is your team? Investigating gender and nationality diversity in GitHub teams". Journal of Software Engineering Research and Development. Vol. $5 \mathrm{~N}^{\circ}$ 1, pp. 1-18. 2017.

[10] M. Hertzum. "The importance of trust in software engineers' assessment and choice of information sources". Information and Organization. Vol. $12 \mathrm{~N}^{\mathrm{o}}$ 1, pp. 1-18. 2002.

[11] N.B. Moe and D. Šmite. "Understanding a lack of trust in Global Software Teams: A multiple-case study". Software Process: Improvement and Practice. Vol. $13 \mathrm{~N}^{\mathrm{o}} 3$, pp. 217-231. 2008.

[12] M. Grabowski and K.H. Roberts. "Risk mitigation in virtual organizations". Organization Science. Vol. 10 N$^{\circ}$ 6, pp. 704721. 1999.

[13] P. Kanawattanachai and Y. Yoo. "Dynamic nature of trust in virtual teams". The Journal 
of Strategic Information Systems. Vol. 11 $\mathrm{N}^{\circ}$ 3-4, pp. 187-213. 2002.

[14] L.L. Martins, L.L.Gilson and M.T. Maynard. "Virtual teams: What do we know and where do we go from here?'. Journal of Management. Vol. $30 \mathrm{~N}^{\circ}$ 6, pp. 805-835. 2004.

[15] S.L. Jarvenpaa, T.R. Shaw and D.S. Staples. "Toward contextualized theories of trust: The role of trust in global virtual teams". Information Systems Research. Vol. $15 \mathrm{~N}^{\mathrm{o}} 3$, pp. 250-267. 2004.

[16] R.C. Mayer, J.H. Davis and F.D. Schoorman. "An integrative model of organizational trust". Academy of management review. Vol. $20 \mathrm{~N}^{\circ}$ 3, pp. 709-734. 1995.

[17] J.D. Lewis and A. Weigert. "Trust as a social reality”. Social Forces. Vol. $63 \mathrm{~N}^{\circ} 4$, pp. 967-985. 1985.

[18] W.R. Clark, L.A. Clark and K. Crossley. "Developing multidimensional trust without touch in virtual teams". Marketing Management Journal.Vol. $20 \mathrm{~N}^{\mathrm{o}}$ 1, 177-193. 2010.

[19] J. Wilson, S. Straus and B. McEvily. "All in due time: The development of trust in computer mediated and face-to-face teams". Organizational Behavior and Human Decision Processes. Vol. 99 No 1, pp. 16-33. 2006.

[20] D.J. McAllister. "Affect and cognitionbased trust as foundations for interpersonal cooperation in organisations". Academy of Management J. Vol. 38 No 1, pp. 25-59. 1995.

[21] M.A, Rothenberger, Y.C. Kao and L. N. Van Wassenhove. "Total quality in software development: An empirical study of quality drivers and benefits in Indian software projects". Information \& Management. Vol. 47 No 7-8, pp. 372-379. 2010.

[22] A. Gopal, M.S. Krishnan, T. Mukhopadhyay and D.R. Goldenson. "Measurement programs in software development: Determinants of success". IEEE Transactions on Software Engineering. Vol. $28 \mathrm{~N}^{\circ}$ 9, pp. 863-875. 2002.

[23] F.Q.B. da Silva, R. Prikladnicki, A.C.C. França, C.V.F. Monteiro, C. Costa and R. Rocha. "An evidence-based model of distributed software development project management: Results from a systematic mapping study". Journal of Software: Evolution and Process. Vol. 24 $\mathrm{N}^{\circ}$ 6, pp. 625-642. 2012.

[24] N.B. Moe, D.S. Cruzes, T. Dybå and E. Engebretsen. "Coaching a Global
Agile Virtual Team”. 2015 IEEE 10th International Conference on Global Software Engineering. Vol. 1, pp. 33-37. Washington. USA. 2015.

[25] D. Thomas and R. Bostrom. "Building Trust and Cooperation Through Technology Adaptation in Virtual Teams: Empirical Field Evidence". Information Systems Management. Vol. $25 \mathrm{~N}^{\circ}$ 1, pp. 45-56. 2010.

[26] A.L. McNab, K.A. Basoglu, S. Sarker and Y. Yu. "Evolution of cognitive trust in distributed software development teams: A punctuated equilibrium model". Electronic Markets. Vol. 22 N$^{\circ}$ 1, pp. 21-36. 2012.

[27] F. Calefato, D. Gendarmi and F. Lanubile. "Embedding Social Networking Information into Jazz to Foster Group Awareness within Distributed Teams". 2nd Int Workshop on Social Software Engineering and Applications. Vol. 1, pp. 23-28. 2009.

[28] V. Casey. "Developing trust in virtual software development teams". Journal of Theoretical and Applied Electronic Commerce Research. Vol. $5 \mathrm{~N}^{\circ}$ 2, pp. 41-58. 2010.

[29] R. Ocker. "Enhancing Learning Experiences in Partially Distributed Teams: Training Students to Work Effectively Across Distances". 42nd Hawaii International Conference on System Sciences. Vol. 1, pp. 1-10. Washington, USA.

[30] B. Kitchenham, D. Budgen and P. Brereton. "Evidence-based software engineering and systematic reviews". CRC Press. Vol. 4. 2015.

[31] M. Niazi, N. Ikram, M. Bano, S. Imtiaz and S.U. Khan. "Establishing trust in offshore software outsourcing relationships: An exploratory study using a systematic literature review". IET software. Vol. $7 \mathrm{~N}^{\circ} 5$, pp. 283293. 2013.

[32] S.G. Zapata, J.L. Barros-Justo, M.R. Romagnano and M. Arrón. "Interpersonal Trust in Virtual Software Development Teams: A Systematic Mapping Study". 46th Simposio Argentino de Ingeniería de Software (ASSE). Vol. 1, pp. 58-66. 2012.

[33] S. Tyagi, R. Sibal and B. Suri. "Role of trust in distributed agile software development teams- A light weight systematic literature review". ICTACT Journal on Management Studies. Vol. 4 N $^{\circ}$ 2, pp. 748-753. 2018. 
[34] B. Kitchenham. "Procedures for performing systematic reviews". Joint Technical Report. Keele, UK. Vol. 33, pp. 1-26. 2004.

[35] C. Wohlin, P. Runeson, M. Höst, M.C. Ohlsson, B. Regnell and A. Wesslén. "Experimentation in software engineering". Springer Science \& Business Media. 2012.

[36] R. Wieringa, N.A.M. Maiden, N.R. Mead and C. Rolland. "Requirements engineering paper classification and evaluation criteria: A proposal and a discussion". Requir. Eng. Vol. $11 \mathrm{~N}^{\circ}$ 1, pp. 102-107. 2006.

[37] C. Wohlin. "Guidelines for snowballing in systematic literature studies and a replication in software engineering". 18th Int. Conference on Evaluation and Assessment in Software Engineering. Vol. 1, pp. 1-10. 2014.

[38] L. Chen, M. A. Babar and H. Zhang. "Towards Evidence-Based Understanding of Electronic Data Sources". 14th International Conference on Evaluation and Assessment in Software Engineering. Vol. 1, pp. 135-138. 2010.

[39] J. Bailey, C. Zhang, D. Budgen, M. Turner and S. Charters. "Search engine overlaps: Do they agree or disagree?". 2nd International Workshop on Realising Evidence-Based Software Engineering REBSE'07. Vol. 1, pp. 1-6. 2007.

[40] T. Dyba, T. Dingsoyr and G.K. Hanssen. "Applying systematic reviews to diverse study types: An experience report". Proceedings Empirical Software Engineering and Measurement. Vol. 1, pp. 225-234. 2007.

[41] K. Petersen, S. Vakkalanka and L. Kuzniarz. "Guidelines for conducting systematic mapping studies in software engineering: An update". Information and Software Technology. Vol. 64, pp. 1-18. 2015.

[42] B. Boehm. "Get ready for agile methods with care". Computer. Vol. $35 \mathrm{~N}^{\circ}$ 1, pp. 64-69. 2002.

[43] J. Popay, H. Roberts, A. Sowden, M. Petticrew, L. Arai, M. Rodgers and S. Duffy. "Guidance on the conduct of narrative synthesis in systematic reviews". A Product from the ESRC Methods Programme. Vol. 1, b92. 2006.

[44] M. Deutsch. "Trust and suspicion, Journal of Conflict Resolution”. Vol. 2 No 4, pp. 265-279. 1958.

[45] S.L. Jarvenpaa and D.E. Leidner. "Communication and trust in global virtual teams".
Organization Science. Vol. 10 N$^{\circ}$ 6, pp. 791 815. 1999.

[46] G. Hertel, U. Konradt and B. Orlikowski. "Managing distance by interdependence: Goal setting, task interdependence and team-based rewards in virtual teams". European Journal of Work and Organizational Psychology. Vol. $13 \mathrm{~N}^{\mathrm{o}}$ 1, pp. 1-28. 2004.

[47] S.L. Jarvenpaa, K. Knoll and D.E. Leidner. "Is anybody out there? Antecedents of trust in global virtual teams". Journal of Management Information Systems. Vol. 14 No 4, pp. 29-64. 1998.

[48] F.Y. Kuo and C.P. Yu. "An exploratory study of trust dynamics in work-oriented virtual teams". J. Comput. Mediated Commun. Vol. $14 \mathrm{~N}^{\circ}$ 4, pp. 823-854. 2009.

[49] B. Al-Ani, H. Wilensky, D. Redmiles and E. Simmons. "An understanding of the role of trust in knowledge seeking and acceptance practices in distributed development teams". 6th IEEE International Conference on Global Software Engineering (ICGSE). Vol. I, pp. 25-34. 2011.

[50] E. Rusman, J. van Bruggen, P. Sloep and P.R. Koper. "Fostering trust in virtual project teams: Towards a design framework grounded in a TrustWorthiness ANtecedents (TWAN) schema. Int. J. Hum. Comput. Stud. Vol. $68 \mathrm{~N}^{\circ}$ 11, pp. 834-850. DOI: 10.1016/j. ijhcs.2010.07.003. 2010.

[51] P. Turek, A. Wierzbicki, R. Nielek, A. Hupa and A. Datta. "Learning about the quality of teamwork from wikiteams". IEEE 2nd International Conference on Social Computing (SocialCom). Vol. 1, pp. 17-24. 2010.

[52] L.E. Scissors, A.J. Gill and D. Gergle. "Linguistic mimicry and trust in text-based CMC". ACM Conference on Computer Supported Cooperative Work. Vol. 1, pp. 277 280. New York, USA. 2008.

[53] G.S. Gure. "Different scale construction approaches used to attitude measurement in social science research". International Journal of Research in Economics and Social Sciences. Vol. 5 No 1, pp. 26-44. 2015.

[54] L. Tan, A. Hindle. "Guest Editorial: Special Section on Mining Software Repositories". Empirical Software Engineering. Vol. 24, pp. 1-3. 2019. 
[55] S. Jalali, C. Gencel, D. Šmite. "Trust dynamics in global software engineering". ACM-IEEE International Symposium on Empirical Software Engineering \& Measurement. Vol. 1, pp. 1-19. 2010.

[56] M. Muethel, F. Siebdrat and M. Hoegl. "When do we really need interpersonal trust in globally dispersed new product development teams?". R\&D Management. Vol. $42 \mathrm{~N}^{\circ}$ 1, pp. 31-46. 2012.

[57] W.S. Humphrey. "Managing the software process". Addison-Wesley Longman Publishing. Boston. 1989.

[58] K. Beck, M. Beedle, A. Van Bennekum, A. Cockburn, W. Cunningham, et al. "Manifesto for agile software development". URL: http:// agilemanifesto.org/

[59] K.W. Miller and D.K. Larson. "Agile software development: Human values and culture". IEEE Technology and Society Magazine. Vol. $24 \mathrm{~N}^{\mathrm{o}}$ 4, pp. 36-42. 2005.

[60] B. Al-Ani, S. Marczak, D. Redmiles and R. Prikladnicki. "Facilitating contagion trust through tools in Global Systems Engineering teams". Information and Software Technology. Vol. $56 \mathrm{~N}^{\circ}$ 3, pp. 309-320. 2014.

[61] J. Cohen. "A coefficient of agreement for nominal scales". Educational and Psychological Measurement. Vol. $20 \mathrm{~N}^{\circ} 1$, pp. 37-46. 1960.

[62] H. P. Andres. "A comparison of face-to-face and virtual software development teams". Team Perform. Manage. Int. J. Vol. $8 \mathrm{~N}^{\mathrm{o}} 1$, pp. 39-48. 2002.

\section{Selected Studies}

[63] F. Calefato, F. Lanubile and N. Novielli. "A preliminary analysis on the effects of propensity to trust in distributed software development". 12th international conference on global software engineering (ICGSE). Vol. 1, pp. 56-60. 2017.

[64] F. Calefato and F. Lanubile. "Affective trust as a predictor of successful collaboration in distributed software projects". IEEE/ACM 1st International Workshop on Emotional Awareness in Software Engineering. Vol. 1, pp. 3-5. 2016.
[65] B. Al-Ani, H. Wilensky, D. Redmiles and E. Simmons. "An understanding of the role of trust in knowledge seeking and acceptance practices in distributed development teams". 6th IEEE International Conference on Global Software Engineering (ICGSE). Vol. 1, pp. 25-34. 2011.

[66] G.A.M. da Cruz, E. H. Moriya-Huzita and V.D. Feltrim. "ARSENAL-GSD: A framework for trust estimation in virtual teams based on sentiment analysis". Information and Software Technology. Vol. 95, pp. 46-61. 2018.

[67] Y. Wang and D. Redmiles. "Cheap talk, cooperation, and trust in global software engineering". Empirical Software Engineering. Vol. 21 N $^{\circ}$ 6, pp. 2233-2267. 2016.

[68] P. Björndal, K. Smiley and P. Mohapatra. "Global software project management: A case study". Proceedings International Conference on Software Engineering Approaches for Offshore and Outsourced Development. Vol. 1, pp. 64-70. 2010.

[69] J. Bisbe and P. Sivabalan. "Management control and trust in virtual settings: A case study of a virtual new product development team". Management Accounting Research. Vol. 3, pp. 12-29. 2017.

[70] V. El Khatib, S.T. Trang, K. Reimers and L. Kolbe. "The role of motivational factors in distributed software development teams: An empirical investigation". 21st European Conference on Information Systems ECIS. Vol. 1, pp. 221. 2013.

[71] S. Jalali, C. Gencel and D. Šmite. "Trust dynamics in global software engineering". 2010 ACMIEEE International Symposium on Empirical Software Engineering and Measurement. Vol. 1, pp 1-19. 2010.

[72] M.Alsharo, D. Gregg and R. Ramirez. "Virtual team effectiveness: The role of knowledge sharing and trust". Information \& Management. Vol. $54 \mathrm{~N}^{\mathrm{o}}$ 4, pp. 479-490. 2017.

[73] M. Muethel, F. Siebdrat and M. Hoegl. "When do we really need interpersonal trust in globally dispersed new product development teams?". R\&D Management. Vol. $42 \mathrm{~N}^{\mathrm{o}}$ 1, pp. 31-46. 2012. 